\title{
Co-Sc (Cobalt-Scandium)
}

\section{H. Okamoto}

The Co-Sc phase diagram in [Massalski2] was redrawn from [Moffatt], which is based on the work of [1978Mar]. The liquidus boundary was drawn as if it was speculative (with a dashed line) in the original diagram, but it was actually determined by DTA measurements.

[2008Liu] calculated the Co-Sc phase diagram based on the [Massalski2] diagram. The result is shown in Fig. 1.

\section{References}

1978Mar: V.Ya. Markiv, I.S. Gavrilenko, V.V. Pet'kov, and N.N. Belyavina, Phase Diagrams of the Systems Sc- $\{\mathrm{Co}, \mathrm{Ni}, \mathrm{Cu}\}, \mathrm{Izv}$. Akad. Nauk SSSR, Met., 1978, 73, p 39-45, in Russian

2008Liu: X.J. Liu, P. Yu, C.P. Wang, and K. Ishida, Thermodynamic Evaluation of the $\mathrm{Co}-\mathrm{Sc}$ and $\mathrm{Fe}-\mathrm{Sc}$ Systems. J. Alloys Compd., 2008, 466, p 169-175

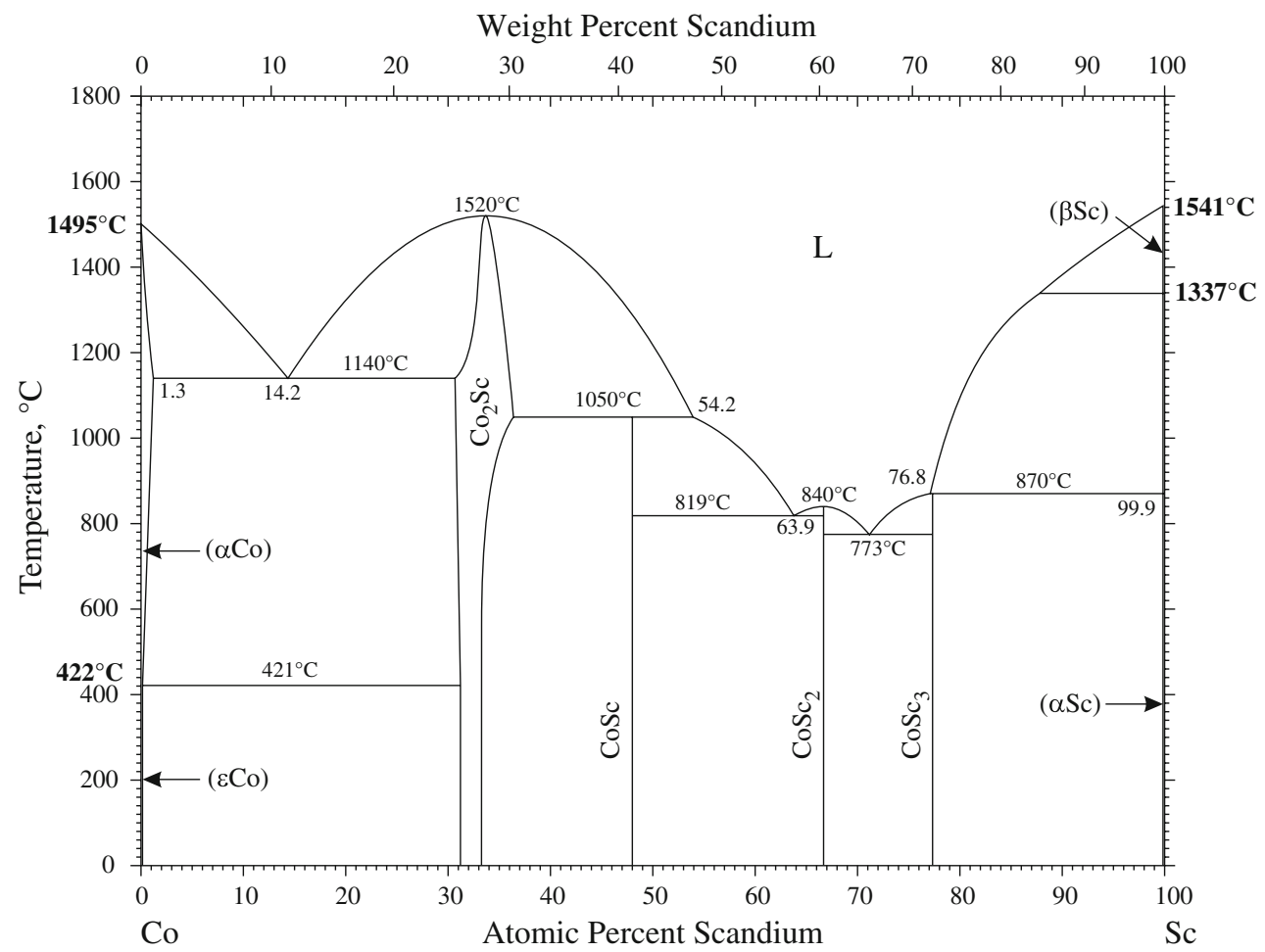

Fig. 1 Co-Sc phase diagram 